\title{
Different Genres and Proficiency Levels: Relationships Among Syntactic Complexity, Genres and Students with Different L2 Proficiency Levels
}

\author{
Minwei Yan $^{1} \&$ Fangfang Zou ${ }^{1}$ \\ ${ }^{1}$ School of Foreign Language, Jiangxi Normal University, Nanchang, China \\ Correspondence: Minwei Yan, 99\#Ziyang Road, Jiangxi Normal University, Nanchang, Jiangxi Province, China. \\ E-mail: ymw0820@163.com
}

Received: October 24, 2019 Accepted: November 15, 2019 Online Published: November 29, 2019

doi:10.5539/ells.v9n4p85 URL: https://doi.org/10.5539/ells.v9n4p85

This research belongs to postgraduates' innovation fund project of Jiangxi Normal University supported by Jiangxi Education Department.

\begin{abstract}
The present study examines differences in syntactic complexity in English writing among writers at different levels and explores the relationship between syntactic complexity and writings with different genres. 20 students in grade three of a senior high school that were randomly selected from two brands of test scores were grouped into high and low proficiency groups. The 40 writings from the 20 students were examined. Writings were evaluated by L2SCA (L2 Syntactic Complexity Analyzer) gauging syntactic complexity at global, clausal and phrasal level. After obtaining the data, the complexity values were entered into SPSS 21.0 to do analysis. Results reveal that the difference of the two genres reaches a significant level in terms of $\mathrm{C} / \mathrm{T}$ (clauses per T-unit) and $\mathrm{CN} / \mathrm{C}$ (complex nominals per clause); there is no significant relationship between syntactic complexity and L2 proficiency levels and no significant interactive effect is found between the genre factor and proficiency factor. The results can yield implications for ESL writing pedagogy.
\end{abstract}

Keywords: syntactic complexity, genre, L2 proficiency level

\section{Introduction}

Over the past few decades, L2 writing has played an important role in EFL research. The triad of CAF (complexity, accuracy and fluency) has long been recognized as a significant assessment measure for L2 writing quality ( $\mathrm{Lu} \& \mathrm{Ai}, 2015)$. Syntactic complexity, as an integral part of the dimension of complexity, is regarded as an important assessment aspect of L2 writing because the development of L2 learners' target language is closely connected with the production's syntactic repertoire. It is evidenced by a lot of studies that have examined the relationship between syntactic complexity of L2 writing and L2 writing quality (e.g., Ortega, 2003; Lu, 2011; Bulté \& Housen, 2014).

Meanwhile, many studies have found that syntactic complexity in L2 writing can be influenced by many factors, such as genre, individual's cognitive style, L2 proficiency, topic and so on (e.g., Ortega, 2003; Beers \& Nagy, 2007; Lu, 2011; Yang et al., 2015), these studies have given our insights into the relationship between syntactic complexity and these factors. The present study is to examine the relationships among syntactic complexity, different genres and students with different L2 proficiency levels.

Therefore, in theory, the present study on exploring the relationship between syntactic complexity and proficiency levels and the impact of genre on syntactic complexity can enrich the research on syntactic complexity by verifying the uniformity of results of other researchers' findings. In practice, the teachers can provide appropriate pedagogical helps for students at different proficiency levels to improve narrative and expository writings' syntactic complexity. 


\section{Literature Review}

\subsection{Definition}

As an important dimension of complexity, syntactic complexity has experienced a long process in its definition. At first, Gaise (1980) defined syntactic complexity as the ability to express more ideas and more thoughts with the use of fewer words, Skehan (1996) defined syntactic complexity as more elaborate language and more various sentence patterns. Wolfe-Quintero et al. (1998) provided a rather clear definition, syntactic complexity was the range of forms that surface in language production and the degree of sophistication of such forms. It means that both variation and sophistication are inseparable elements. Ortega (2003) held the similar view. Lu (2011) defined it as the range of syntactic structures produced and the degree of sophistication of such structures.

\subsection{Related Studies on the Relationships Among Syntactic Complexity, Genre and L2 Proficiency Level}

Among the factors influencing syntactic complexity, genre and L2 proficiency level are often studied, there are many studies on the two aspects. In the aspect of genre, Berman and Nir-Sagiv (2004) compared personal-experience narrative and expository texts in writing and speaking. They found that expository texts represented more complexity than narrative ones in lexical and grammar, expository texts had more complex noun phrases, relative clauses and more abstract words. Beers and Nagy (2007) examined the relationship between the quality of narratives and essays and different syntactic complexity measures. They found that essays have more words per T-unit than narratives. Beers and Nagy (2010) examined the genre differences among narrative, descriptive, contrast and persuasive texts through two syntactic complexity measures: clauses per T-unit and words per clause, they were written by 83 students in grades three, five and seven. The findings showed that persuasive texts at each grade represented more clauses per T-unit than the other three genres and descriptive texts at each grade showed more words per clause than the persuasive essays. Yoon and Polio (2016) conducted a longitudinal research to investigate the genre difference of narrative and persuasive texts, the results showed that the syntactic complexity of persuasive texts at phrasal level increased and narratives had more clausal subordination.

As for the aspect of L2 proficiency level. Ortega (2003) found that the syntactic complexity was related to writers' overall L2 proficiency, but the second or foreign language learning context and criterion for proficiency should be taken into account. Lu (2011) studied a corpus of more than three thousand essays written by Chinese English majors from four grades to identity the syntactic complexity measures that significantly differentiated between school levels. He found that mean length of clause, mean length of sentence, mean length of T-unit, complex nominals per clause and complex nominals per T-unit were related to learners' proficiency levels. Lahuerta Martínez (2018) examined syntactic complexity differences in English writings by lower intermediate and intermediate secondary education writers. He found that learners at intermediate proficiency level outperformed the learners at lower intermediate level in almost all the syntactic complexity measures used at global, clausal and phrasal levels.

\subsection{Summary}

As the literature above, syntactic complexity can be an indicator of L2 writing quality and L2 proficiency. The research of syntactic complexity in writing has made great progress, with genre and L2 proficiency level involved, but most studies evaluated different proficiency levels based on different grades or on certain criterion employed on a group of learners. These studies, though constructive, have little pedagogical implications in real teaching, because the English teachers always want to improve the writing competence of the students with writing difficulties. Therefore, the present study divides the students in the same grade into different L2 proficiency level. As for the aspect of genre, syntactic complexity studies on the genre differences are relatively incomplete except for some studies and the studies focusing on narrative and expository are rare, and narrative and expository are the most common genres for senior high school students. In order to further fill the gap, this present study examines the relationships among syntactic complexity, narrative and expository genres and L2 proficiency level.

\section{Method}

\subsection{Research Questions}

This study, therefore, explores the relationships among syntactic complexity, genres and different proficiency levels. Based on the purpose which has mentioned before, there are certain research questions in this study:

1) Are there any genre differences in syntactic complexity between narrative and expository genre?

2) Are there any significant differences between syntactic complexity and different proficiency levels? 
3) Are there any interactive effects in the syntactic complexity between narrative and expository writings in high and low proficiency levels?

\subsection{Participants}

The participants in this study are 20 students at high or low proficiency level in grade three from a senior high school. The criterion to distinguish proficiency levels was that students who got 120-150 in the English final exam are considered excellent, those who got 100-120 are good, 90-100, qualified. In the present study, 10 students that were randomly selected from those who got 120-150 were considered at high proficiency level and 10 students that were randomly selected from those who got below 90 were considered at low proficiency level.

\subsection{Tools}

The study uses the tool L2 Syntactic Complexity Analyzer (L2SCA), which was invented by Lu Xiaofei in 2010. He summarized the 14 indexes from the literature of Wolfe-Quintero et al. (1998) and Ortega (2003).

\subsection{Data Collection}

The data came from the writings of 20 students. They were asked to write a narrative and an expository writing in one class, the title of narrative writing was "Please write a story about an unforgettable experience" and the title of expository writing was "Please write an exposition about your hometown". Students didn't know the usage of their writings, and then, these writings were coded into plain files individually. Finally, the writings files were put into L2SCA to calculate the values of corresponding measures of syntactic complexity.

\subsection{Syntactic Complexity Measures}

Regarding the syntactic complexity measures, the present study follows Norris and Ortega's (2009) recommendation to measure syntactic complexity as a multidimensional construct, involving global, clausal and phrasal sub-constructs. And Table1 lists the four measures of syntactic complexity

Table 1. Syntactic complexity measures in this study

\begin{tabular}{lll}
\hline Dimension & Measure name & Label \\
\hline Global & Mean length of T-unit & MLT \\
Clausal (coordination) & T-units per sentence & T/S \\
Clausal (subordination) & Clauses per T-unit & $\mathrm{C} / \mathrm{T}$ \\
Phrasal & Complex nominals per clause & $\mathrm{CN} / \mathrm{C}$ \\
\hline
\end{tabular}

\subsection{Data Analysis}

Quantitative analysis was employed in this study by SPSS 21.0. Description statistics was used to show the distribution of frequencies of the corresponding syntactic complexity indices. T-Test was employed to evaluate whether the effects of genre and proficiency level were statistically significant and Repeated Measured ANOVA were utilized to investigate whether there were interactive effects between genre and proficiency level.

\section{Results and Discussion}

\subsection{The Effect of Genre on the Written Syntactic Complexity}

\subsubsection{The Effect of Genre on Syntactic Complexity at the Global Level}

As mentioned before, syntactic complexity measures at global level refers to MLT in the present study. To explore the influence brought by genre difference, that is, narrative writing and expository writing, on MLT, the researcher at first conducted a descriptive analysis. The results in these writings is displayed as follows in the Table 2.

Table 2. Descriptive analysis of MLT in narrative writings and expository writings

\begin{tabular}{lllllllll}
\hline & HN & & HE & & LN & & LE & \\
\hline & M & S.D. & M & S.D. & M & S.D. & M & S.D. \\
MLT & 11.81 & 3.01 & 13.15 & 2.84 & 12.43 & 3.08 & 10.93 & 1.88 \\
\hline
\end{tabular}

Note. $\mathrm{HN}=$ narrative writings of high proficiency level; $\mathrm{HE}=$ expository writings of high proficiency level; $\mathrm{LN}=$ narrative writings of low proficiency level; LE=expository writings of low proficiency level; MLT=mean length of T-unit.

As is shown in the above table, the mean words per T-unit of narrative writings are higher than that of expository 
ones at high proficiency level. However, narrative writings by low proficiency level students show longer T-units.

To examine whether the difference of MLT in the two genre writings under both high and low proficiency levels reach significant level or not, the Paired Samples T Test is necessary.

Table 3. Difference in MLT in narrative writings and expository writings

\begin{tabular}{llll}
\hline Sample & Index & $\mathrm{t}$ & P value \\
\hline HN-HE & MLT & -1.087 & 0.305 \\
LN-LE & MLT & 1.537 & 0.159 \\
\hline
\end{tabular}

Note. $\mathrm{HN}=$ =narrative writings of high proficiency level; $\mathrm{HE}=$ expository writings of high proficiency level; $\mathrm{LN}=$ narrative writings of low proficiency level; $\mathrm{LE}=$ expository writings of low proficiency level; MLT=mean length of T-unit.

As can be seen in Table 3, there are not significant differences between the narrative writings and expository writings in terms of MLT at both high and low proficiency levels, for $\mathrm{t}=-1.087, \mathrm{p}=0.305>0.05 ; \mathrm{t}=1.537$, $\mathrm{p}=0.159>0.05$. On the basis of the above statistical results, it can be concluded that the genre does not have an influence on the level of T-unit length, it is different from the study of Berman and Nir-Sagiv (2004) which claimed that there was a significant difference between the two genres in MLT, expository texts showed longer T-unit than narrative ones.

The statistical results are understandable for the following reasons: 1) The participants in Berman and Nir-Sagiv's (2004) study were in different grades, so they might be at different proficiency level, which caused a significant difference in terms of MLT. 2) Senior high school students are not familiar with narrative writing and expository writing, owing to the requirement of nationwide college entrance examination, the two genres are not frequently trained in daily teaching programs. As a result, they can't produce longer T-units. 3) The reason why narrative writings by students of low proficiency level produce longer T-units than expository writings are that expository writing is highly scientific in content and accurate in language, students at relative low proficiency level may lack corresponding ability.

\subsubsection{The Effect of Genre on Syntactic Complexity at the Clausal Level}

Syntactic complexity was measure by T-units per sentence $(\mathrm{T} / \mathrm{S})$ and clauses per T-unit $(\mathrm{C} / \mathrm{T})$ at clausal level in this study. Table 4 shows the basic statistical analysis results on the two indexes of narrative and expository writing genres between high and low proficiency levels.

Table 4. Descriptive analysis of $\mathrm{T} / \mathrm{S}$ and $\mathrm{C} / \mathrm{T}$ in narrative writings and expository writings

\begin{tabular}{lllllllll}
\hline & HN & & HE & & LN & & LE & \\
\hline & M & S.D. & M & S.D. & M & S.D. & M & S.D. \\
$\mathrm{T} / \mathrm{S}$ & 1.12 & 0.13 & 1.11 & 0.12 & 1.19 & 0.13 & 1.17 & 0.17 \\
$\mathrm{C} / \mathrm{T}$ & 1.53 & 0.20 & 1.49 & 0.25 & 1.73 & 0.35 & 1.41 & 0.19 \\
\hline
\end{tabular}

Note. $\mathrm{HN}=$ narrative writings of high proficiency level; HE=expository writings of high proficiency level; $\mathrm{LN}=$ narrative writings of low proficiency level; $\mathrm{LE}=$ expository writings of low proficiency level; $\mathrm{T} / \mathrm{S}=\mathrm{T}$-units per sentence; $\mathrm{C} / \mathrm{T}=$ clauses per T-unit.

From the Table 4, it can be seen that in high proficiency group, not only T-units per sentence (T/S) but also clauses per T-unit $(\mathrm{C} / \mathrm{T})$ in narrative writings are higher than expository writings; moreover, in low proficiency group the statistical results remain the same in both T/S and C/T. According to the results, Paired Samples T Test is conducted to see whether the differences between narrative writings and expository writings in $\mathrm{T} / \mathrm{S}$ and $\mathrm{C} / \mathrm{T}$ at both proficiency levels are significant or not.

Table 5. Differences in $\mathrm{T} / \mathrm{S}$ and $\mathrm{C} / \mathrm{T}$ in narrative writings and narrative writings

\begin{tabular}{llll}
\hline Sample & Index & $\mathrm{t}$ & P value \\
\hline HN-HE & $\mathrm{T} / \mathrm{S}$ & 0.530 & 0.609 \\
& $\mathrm{C} / \mathrm{T}$ & 0.333 & 0.747 \\
LN-LE & $\mathrm{T} / \mathrm{S}$ & 0.241 & 0.815 \\
& $\mathrm{C} / \mathrm{T}$ & 2.306 & 0.047 \\
\hline
\end{tabular}

Note. $\mathrm{HN}=$ narrative writings of high proficiency level; $\mathrm{HE}=$ expository writings of high proficiency level; LN=narrative writings of low proficiency level; LE=expository writings of low proficiency level; $\mathrm{T} / \mathrm{S}=\mathrm{T}$-units per sentence; $\mathrm{C} / \mathrm{T}=\mathrm{clauses}$ per $\mathrm{T}$-unit. 
Based on Table 5, only the difference of $\mathrm{C} / \mathrm{T}$ between narrative and expository writings in low proficiency group is significant for $\mathrm{t}=2.306, \mathrm{p}=0.047<0.05$.

The results we get are different from Berman and Nir-sagiv's (2004) study in which they claimed that expository texts had more syntactic complexity at clausal level.

The following are possible reasons which can support the different results. 1) It may be due to the small sampling size of my paper, it only investigates 20 students, but in Berman and Nir-Sagiv' (2004) study, it had 80 subjects. 2) $\mathrm{C} / \mathrm{T}$ belongs to subordinated clauses. In order to write a story, the students tended to rely on more adverbial clauses to elaborate the time and place clearly. Therefore, the index of $\mathrm{C} / \mathrm{T}$ in narrative writings is higher. 3) T/S belongs to coordinated clauses. The unfamiliarity of the subjects towards the expository writings plays an important role in the lower $\mathrm{T} / \mathrm{S}$ index of expository texts in both high and low proficiency levels. According to Skehan and Foster's Limited Attentional Capacity Model (1999), the learners' total cognitive resources are limited, so paying too much attention to one aspect may leads to the ignorance of other aspects. In expository writings, the subjects firstly considered the content, so the complexity of language production decreased.

\subsubsection{The Effect of Genre on Syntactic Complexity at the Phrasal Level}

Syntactic complexity at phrasal level was measured by complex nominals per clause $(\mathrm{CN} / \mathrm{C})$ in the present study. Table 6 shows the descriptive analysis results on this index.

Table 6. Descriptive statistics of $\mathrm{CN} / \mathrm{C}$ in narrative writings and expository writings

\begin{tabular}{lllllllll}
\hline & HN & & HE & & LN & \multicolumn{3}{c}{ LE } \\
\hline & M & S.D. & M & S.D. & M & S.D. & M & S.D. \\
CN/C & 0.73 & 0.19 & 1.08 & 0.29 & 0.59 & 0.18 & 0.89 & 0.34 \\
\hline
\end{tabular}

Note. $\mathrm{HN}=$ narrative writings of high proficiency level; HE=expository writings of high proficiency level; LN=narrative writings of low proficiency level; $\mathrm{LE}=$ expository writings of low proficiency level; $\mathrm{CN} / \mathrm{C}=$ complex nominals per clause.

As the above Table 6 indicates, in both high and low proficiency groups, narrative writings promote fewer complex nominals per clause than expository writings. In view of the roughness in this statistical results, Paired Samples $\mathrm{T}$ Test analysis is necessary to find out whether the difference of $\mathrm{CN} / \mathrm{C}$ in the two genres reach significant or not.

Table 7. Difference in $\mathrm{CN} / \mathrm{C}$ in narrative writings and expository writings

\begin{tabular}{llll}
\hline Sample & Index & $\mathrm{t}$ & P value \\
\hline HN-HE & $\mathrm{CN} / \mathrm{C}$ & -2.830 & 0.020 \\
LN-LE & $\mathrm{CN} / \mathrm{C}$ & -3.704 & 0.005 \\
\hline
\end{tabular}

Note. $\mathrm{HN}=$ narrative writings of high proficiency level; $\mathrm{HE}=$ expository writings of high proficiency level; $\mathrm{LN}=$ narrative writings of low proficiency level; $\mathrm{LE}=$ expository writings of low proficiency level; $\mathrm{CN} / \mathrm{C}=$ complex nominals per clause.

As can be seen in Table 7, in both high and low proficiency groups, the $\mathrm{CN} / \mathrm{C}$ index in narrative writings is significantly different from that in expository writings, for $\mathrm{t}=-2.830, \mathrm{p}=0.020<0.05 ; \mathrm{t}=-3.704, \mathrm{p}=0.005<0.05$.

It can be seen from the above two tables that there are significant differences between the narrative writings and expository writings in both high and low proficiency groups in terms of $\mathrm{CN} / \mathrm{C}$, it can be concluded that the genre does have a significant effect on $\mathrm{CN} / \mathrm{C}$, which is similar to the Berman and Nir-Sagiv's finding that expository texts had more complex nominals than narrative texts (Berman \& Nir-Sagiv, 2004).

Certain reason can justify these statistical results: Narrative writing stresses the description of plots and details so that the students put more attention on the creativity of plots and ignored the usage of complex noun phrases. While in expository writing, it requires concise and clear expression which forces students to use complex nominals. Therefore, it makes the $\mathrm{CN} / \mathrm{C}$ differences significant in the two genres.

\subsection{The Effect of Proficiency Level on Written Syntactic Complexity}

The present study divides the learners into two proficiency groups based on certain criteria: high proficiency level (HP) and low proficiency level (LP). The present study aims at exploring the relationship between proficiency level and syntactic complexity. In the following three sections, the statistical results are presented 
and discussed.

4.2.1 The Effect of Proficiency Level on Syntactic Complexity at the Global Level

Table 8. Descriptive statistics of MLT in writings of HP and LP

\begin{tabular}{lllllllll}
\hline & HN & & LN & & HE & \multicolumn{3}{l}{ LE } \\
\hline & M & S.D. & M & S.D. & M & S.D. & M & S.D. \\
MLT & 11.81 & 3.01 & 12.43 & 3.08 & 13.15 & 2.84 & 10.93 & 1.88 \\
\hline
\end{tabular}

Note. $\mathrm{HN}=$ narrative writings of high proficiency level; HE=expository writings of high proficiency level; $\mathrm{LN}=$ narrative writings of low proficiency level; LE=expository writings of low proficiency level; MLT=mean length of T-unit.

As we can see in this table, in regard to narrative writings, the high proficiency group produced shorter T-units than low proficiency group, which is opposite to the expository writings.

Table 9. Differences in MLT in writings of HP and LP

\begin{tabular}{llll}
\hline Sample & Index & $\mathrm{t}$ & P value \\
\hline HN-LN & MLT & -0.456 & 0.654 \\
HE-LE & MLT & 2.065 & 0.054 \\
\hline
\end{tabular}

Note. $\mathrm{HN}=$ narrative writings of high proficiency level; HE=expository writings of high proficiency level; LN=narrative writings of low proficiency level; LE=expository writings of low proficiency level; MLT=mean length of T-unit.

From Table 9, it can be noticed that for both narrative and expository writings, the MLT index of HP isn't significantly different from that of $\mathrm{LP}$, for $\mathrm{t}=-0.456, \mathrm{p}=0.654 ; \mathrm{t}=2.065, \mathrm{p}=0.054$.

The reason why the high proficiency group produced shorter T-units than low proficiency group in narrative writings may be that students at low proficiency level might try to make their writings more complex, while students at high proficiency level might pay more attention to the development of the whole plot.

\subsubsection{The Effect of Proficiency Level on Syntactic Complexity at the Clausal Level}

Table 10. Descriptive statistics of T/S and $\mathrm{C} / \mathrm{T}$ in writings of HP and LP

\begin{tabular}{lllllllll}
\hline & HN & & LN & & HE & & LE & \\
\hline & $\mathrm{M}$ & S.D. & M & S.D. & M & S.D. & M & S.D. \\
$\mathrm{T} / \mathrm{S}$ & 1.12 & 0.13 & 1.19 & 0.13 & 1.11 & 0.12 & 1.17 & 0.17 \\
$\mathrm{C} / \mathrm{T}$ & 1.53 & 0.20 & 1.73 & 0.35 & 1.49 & 0.25 & 1.41 & 0.19 \\
\hline
\end{tabular}

Note. $\mathrm{HN}=$ narrative writings of high proficiency level; $\mathrm{HE}=$ expository writings of high proficiency level; $\mathrm{LN}=$ narrative writings of low proficiency level; $\mathrm{LE}=$ expository writings of low proficiency level; $\mathrm{T} / \mathrm{S}=\mathrm{T}$-units per sentence; $\mathrm{C} / \mathrm{T}=$ clauses per T-unit.

As is shown in Table 10, with respect to narrative writings, the high proficiency group motivated lower clausal indexes in their writings than the low proficiency group. On the other hand, for the expository writings, the T/S index of high proficiency group is lower than that of low proficiency group, but the statistic result in terms of the $\mathrm{C} / \mathrm{T}$ index is opposite.

Table 11. Differences in T/S and $\mathrm{C} / \mathrm{T}$ in writings of HP and LP

\begin{tabular}{llll}
\hline Sample & Index & $\mathrm{t}$ & $\mathrm{P}$ value \\
\hline HN--LN & $\mathrm{T} / \mathrm{S}$ & -1.153 & 0.246 \\
& $\mathrm{C} / \mathrm{T}$ & -1.771 & 0.094 \\
HE--LE & $\mathrm{T} / \mathrm{S}$ & -1.031 & 0.316 \\
& $\mathrm{C} / \mathrm{T}$ & 1.313 & 0.206 \\
\hline
\end{tabular}

Note. $\mathrm{HN}=$ narrative writings of high proficiency level; HE=expository writings of high proficiency level; LN=narrative writings of low proficiency level; $\mathrm{LE}=$ expository writings of low proficiency level; $\mathrm{T} / \mathrm{S}=\mathrm{T}$-units per sentence; $\mathrm{C} / \mathrm{T}=$ clauses per T-unit.

According to Table 11, for narrative writings, no significant differences in $\mathrm{T} / \mathrm{S}$ and $\mathrm{C} / \mathrm{T}$ were found in the two proficiency levels, for $\mathrm{t}=-1.153, \mathrm{p}=0.246>0.05 ; \mathrm{t}=-1.771, \mathrm{p}=0.094$. For expository writings, the differences 
brought by proficiency levels in the two indexes are not significant, either, for $t=-1.031, p=0.316 ; t=1.313$, $\mathrm{p}=0.206$.

The above two charts suggest that low proficient students wrote more coordinated sentences in their writings. This result seems to confirm Norris and Ortega (2009) finding that learners of lower L2 proficiency level tended to use more coordinated sentences. And the insignificance is supported by $\mathrm{Lu}$ (2011) who found it difficult to use clausal subordination (especially $\mathrm{C} / \mathrm{T}$ ) and clausal coordination (especially $\mathrm{T} / \mathrm{S}$ ) to distinguish proficiency levels.

Two factors may account for the statistical results: 1) Low proficient students tended to use more clauses in narrative writings because of the genre features of narration, like the time and place, while high proficient students paid more attention to the plot. 2) Wolfe-Quintero et al. (1998) claimed that learners developed their language following the order of coordinate clauses to subordinate clauses, and then to shortening clauses, thus students at higher proficiency level produced less T-units per clause.

4.2.3 The Effect of Proficiency Level on Syntactic Complexity at the Phrasal Level

Table 12. Descriptive statistics of CN/C in writings of HP and LP

\begin{tabular}{lllllllll}
\hline & HN & & LN & & HE & \multicolumn{3}{c}{ LE } \\
\hline & M & S.D. & M & S.D. & M & S.D. & M & S.D. \\
CN/C & 0.73 & 0.19 & 0.59 & 0.18 & 1.08 & 0.29 & 0.89 & 0.34 \\
\hline
\end{tabular}

Note. $\mathrm{HN}=$ narrative writings of high proficiency level; $\mathrm{HE}=$ expository writings of high proficiency level; $\mathrm{LN}=$ narrative writings of low proficiency level; $\mathrm{LE}=$ expository writings of low proficiency level; $\mathrm{CN} / \mathrm{C}=$ complex nominals per clause.

From the above table, we can notice that in both narrative and expository writings, the CN/C index of HP is higher than LP. In order to see whether the differences reach significance, Independent-Samples $\mathrm{T}$ Test is conducted.

Table 13. Differences in CN/C in writings of HP and LP

\begin{tabular}{llll}
\hline Sample & Index & $\mathrm{t}$ & P value \\
\hline HN--LN & $\mathrm{CN} / \mathrm{C}$ & 1.654 & 0.116 \\
HE--LE & $\mathrm{CN} / \mathrm{C}$ & 1.286 & 0.215 \\
\hline
\end{tabular}

Note. $\mathrm{HN}=$ narrative writings of high proficiency level; HE=expository writings of high proficiency level; $\mathrm{LN}=$ narrative writings of low proficiency level; $\mathrm{LE}=$ expository writings of low proficiency level; $\mathrm{CN} / \mathrm{C}=$ complex nominals per clause.

It can be noticed that there is no significance between the two proficiency groups in both narrative and expository writings, for $\mathrm{t}=1.654, \mathrm{p}=0.116>0.05 ; \mathrm{t}=1.286, \mathrm{p}=0.215>0.05$.

What the two tables show is consistent with Norris and Ortega's (2009) study which proposed a hypothesis that L2 learners progress from coordination to subordination and to greater use of phrasal-level complexity. While the results presented in this study doesn't fully lend itself to the trajectory for syntactic development, it is noteworthy that phrasal complexity can distinguish low-rated and high-rated writings.

To conclude, there is no significant relationship between syntactic complexity and proficiency levels in the present study although proficiency does have some influence on the subjects' writings syntactic complexity. The following are some possible reasons which can explain the results: 1) Senior high school students no matter which proficiency stage they are in, are not familiar with the two genres, argumentative writings are the most frequently trained in daily study. According to Limited Attentional Capacity Model, the increase of writing tasks may make students ignore the syntactic complexity. 2) Proficiency sampling criterion may have an impact on the result. Ortega (2003) found that using holistic rating as proficiency criterion produced narrower ranges of syntactic complexity values than using program level as the criterion. 3) Another possible reason could be relatively narrow bands of test scores which led to little proficiency difference in syntactic complexity.

\subsection{The Interactive Effects Between Genre and Proficiency Level on Written Syntactic Complexity}

This section aims at exploring whether there are interactive effects between genre and proficiency level on syntactic complexity. To explore the interactive effects, Repeated Measured ANOVA was utilized. The results are listed in the Table 14. 
Table 14. Results of the repeated measured ANOVA of the four syntactic complexity measures

\begin{tabular}{lllllll}
\hline & Genre & & Proficiency & \multicolumn{2}{c}{ Genre*Proficiency } \\
\hline & F & Sig & F & Sig & F & Sig \\
MLT & 0.1 & 0.923 & 0.721 & 0.407 & 3.260 & 0.880 \\
T/S & 0.207 & 0.655 & 1.957 & 0.179 & 0.001 & 0.980 \\
C/T & 2.371 & 0.141 & 0.755 & 0.396 & 3.889 & 0.064 \\
CN/C & 19.493 & 0.000 & 3.236 & 0.089 & 0.079 & 0.782 \\
\hline
\end{tabular}

From the Table 14, it's apparent that there are no significant interactive effects between the genre factor and proficiency for the $\mathrm{p}>0.05$.

All the outcomes taken into consideration, proficiency factor played a more important role in MLT and T/S than genre factor due to the statistical fact that the main effect brought by proficiency is much bigger than genre factor, for $\mathrm{p}=0.923>\mathrm{p}=0.407$ (MLT), $\mathrm{p}=0.655>\mathrm{p}=0.179(\mathrm{~T} / \mathrm{S})$. However, the main effect of genre factor is bigger than proficiency in $\mathrm{C} / \mathrm{T}$ and $\mathrm{CN} / \mathrm{C}$ indexes due to $\mathrm{p}=0.141<\mathrm{p}=0.369(\mathrm{C} / \mathrm{T}) ; \mathrm{p}=0.000<\mathrm{p}=0.089(\mathrm{CN} / \mathrm{C})$. What's more, the $\mathrm{CN} / \mathrm{C}$ index is a good measure to distinguish the genre differences.

\section{Conclusion}

\subsection{Major Findings}

The present study collected 40 essays in two genres written by 20 senior high school students in high and low proficiency levels, aiming to find out the effect of genre and proficiency level on high school students' written English syntactic complexity and the possible interactive effect between the two factors.

For the first question, the effect of gene on syntactic complexity, the finding is that the difference of the two genres reaches a significant level in terms of $\mathrm{C} / \mathrm{T}$ and $\mathrm{CN} / \mathrm{C}$ because of the different genre features of narrative and expository writings.

As for the second question, the effect of proficiency level on syntactic complexity, the finding is that there is no significant relationship between syntactic complexity and proficiency levels. Three factors may account for this result: Firstly, the students at both high and low proficiency levels are unfamiliar with the the two genres. Secondly, the proficiency sampling criterion may attribute to the result. Finally, the narrow bands of test scores may also play a part.

As for the last question over the interactive effect between the two factors, no significant interactive effect is found between the genre factor and proficiency factor.

\subsection{Pedagogical Implications}

The present study has pedagogical implications that contribute to the teaching of L2 writing.

First, due to the validity of syntactic complexity in L2 writing assessment, English teachers should be aware of its importance and pay more attention to the development of it, encouraging students to use more complex sentences and phrases.

Second, English teachers can be helped to develop pedagogical interventions for students with different proficiency levels to deal with the weak parts in writing in relation to syntactic complexity. In this study, although there is no significant relationship between syntactic complexity and proficiency levels, the teachers in regular class should pay more attention to the gap in syntactic complexity of writing between students of different L2 proficiency levels.

Third, with respect to the genre differences, different genres have different characteristics in syntactic complexity, teachers should take genre differences into consideration and arrange proper activities. As is shown above, narrative writing and expository writing has a genre difference in $\mathrm{CN} / \mathrm{C}$, so in narrative writing, teachers should encourage students to use complex nominals.

\subsection{Limitations of the Study}

First, the sample size is small, which may make the results not generalizable to other ESL learners. Therefore, more samples are needed in the future studies.

Second, the fact that there is only one criterion to distinguish the proficiency groups may influence the research results. It is expected that the future research can use more criteria.

Third, the individual emotion may have effect on the results of syntactic complexity. The students in senior high school seldom write two different writings in one class, so when they write the second writing, they may be 
impatient, which will influence the syntactic complexity results.

Fourth, student's cognition also has impact on the final results. The writing topics of narrative and expository writing are related to students' life, so every student has different understanding about the same topic. And the familiar degree of every student varies about the same topic. Therefore, the student's cognition will influence the value of syntactic complexity.

\section{Acknowledgments}

I am very grateful to my supervisor, it was her advice that my paper can be completed.

\section{References}

Beers, S. F., \& Nagy, W. E. (2007). Syntactic complexity as a predictor of adolescent writing quality: Which measures? Which genre? Reading and Writing, 22(2), 185-200. https://doi.org/10.1007/s11145-007-9107-5

Beers, S. F., \& Nagy, W. E. (2010). Writing development in four genres from grades three to seven: syntactic complexity and genre differentiation. Reading and Writing, 24(2), 183-202. https://doi.org/10.1007/s11145-010-9264-9

Berman, R. A., \& Nir-Sagiv, B. (2004). Linguistic indicators of inter-genre differentiation in late language development. Journal of Child Language, 31, 339-380. https://doi.org/10.1017/S0305000904006038

Biber, D., Gray, B., \& Poonpon, K. (2011). Should we use characteristics of conversation to measure grammatical complexity in L2 writing development? TESOL Quarterly, 45(1), 5-35. https://doi.org/10.5054/tq.2011.244483

Bulté, B., \& Housen, A. (2014). Conceptualizing and measuring short-term changes in L2 writing complexity. Journal of Second Language Writing, 26, 42-65. https://doi.org/10.1016/j.jslw.2014.09.005

Gaise, S. J. (1980). T-unit analysis in second language research: Applications, problems and limitations. TESOL Quarterly, 14, 53-60. https://doi.org/10.2307/3586808

Lahuerta Martínez, A. C. (2018). Analysis of syntactic complexity in secondary education EFL writers at different proficiency levels. Assessing Writing, 35, 1-11. https://doi.org/10.1016/j.asw.2017.11.002

$\mathrm{Lu}, \mathrm{X}$. (2011). A corpus-based evaluation of syntactic complexity measures as indices of college-level ESL writers' language development. TESOL Quarterly, 45(1), 36-62. https://doi.org/10.5054/tq.2011.240859

Lu, X., \& Ai, H. (2015). Syntactic complexity in college-level English writing: Differences among writers with diverse L1 backgrounds. Journal of Second Language Writing, 29, 16-27. https://doi.org/10.1016/j.jslw.2015.06.003

Norris, J. M., \& Ortega, L. (2009). Towards an organic approach to investigating CAF in instructed SLA: The case of complexity. Applied Linguistics, 30(4), 555-578. https://doi.org/10.1093/applin/amp044

Ortega, L. (2003). Syntactic complexity measures and their relationship to L2 proficiency: A research synthesis of college-level L2 writing. Applied Linguistics, 24, 492-518. https://doi.org/10.1093/applin/24.4.492

Skehan, P. (1996). A Framework for the Implementation of Task-based Instruction. Applied linguistics, 17, 38-62. https://doi.org/10.1093/applin/17.1.38

Skehan, P., \& Foster, P. (1999). The Influence of Task Structure and Processing Conditions on Narrative Retellings. Language Learning, 49(1), 93-120. https://doi.org/10.1111/1467-9922.00071

Wolfe-Quintero, K., Inagaki, K. S., \& Kim, H. Y. (1998). Second language development in writing: Measures of fluency, accuracy, and complexity. Honolulu, HI: University of Hawaii Press.

Yang, W., Lu, X., \& Weigle, S. C. (2015). Different topics, different discourse: Relationships among writing topic, measures of syntactic complexity, and judgments of writing quality. Journal of Second Language Writing, 28, 53-67. https://doi.org/10.1016/j.jslw.2015.02.002

Yoon, H.-J., \& Polio, C. (2016). The Linguistic Development of Students of English as a Second Language in Two Written Genres. TESOL Quarterly, 51(2), 275-301. https://doi.org/10.1002/tesq.296

\section{Copyrights}

Copyright for this article is retained by the author, with first publication rights granted to the journal.

This is an open-access article distributed under the terms and conditions of the Creative Commons Attribution license (http://creativecommons.org/licenses/by/4.0/). 